\title{
New Onset Diabetes Mellitus after Living Donor Renal Transplantation: A Unique Pattern in the Egyptian Population
}

Ayman Maher Nagib ${ }^{1 *}$, Ayman Fathi Refaie ${ }^{1}$, Ahmed Ibrahim Akl', Ahmed Hassan Neamatalla1, Mohamed Ashraf Fouda ${ }^{1}$, Mohammed Ade Bakr $^{1}$, Ahmed Abdelrahman Shokeir ${ }^{2}$ and Ehab Wahba Wafa ${ }^{1}$

${ }^{1}$ Department of Nephrology, Urology and Nephrology Center, Egypt

${ }^{2}$ Department of Urology, Urology and Nephrology Center, Egypt

\begin{abstract}
Objectives: Our aim was to identify the diabetic risk profile of new onset diabetes after live donor renal transplantation (NODAT) and its impact on patient and graft survival in Egyptian population.

Patient and methods: A retrospective review of 2019 renal allograft recipients has been performed. Risk factors, medical complications, patient and graft survival were analyzed.

Results: After a mean follow up period of $8.8 \pm 5.8$ years, $450(22.2 \%)$ recipients developed NODAT. A 455 post transplantation time matched control recipients without DM was selected. Time table revealed that $50 \%$ of NODAT cases discovered during the first 6 months post transplantation. The NODAT recipients were significantly older and obese with higher body mass index. Family history of DM was significantly positive among the NODAT group. Cox's multivariate regression analysis revealed that the older age, positive family history of DM, high BMI, HCV infection and hypercholesterolemia were of significant risk factor. Medical complications were significant in the NODAT group. Patient survival was significantly lower in the NODAT group on the other hand the graft survival was comparable.
\end{abstract}

Conclusion: NODAT does not statistically affect the graft survival. But, NODAT is a major problem endangers the patient life and must be minded to consider such patient as especially at higher risk for diabetic complications.

Keywords: Diabetes mellitus; Graft survival; Cox's multivariate regression analysis; Renal allograft

\section{Introduction}

Kidney transplantation is the most cost effective treatment option for patients with ESRD yielding the best quality of life among different renal replacement modalities available to such individuals. Even this treatment option for kidney failure has some complications, one of them being New Onset Diabetes After Transplantation (NODAT). The development of NODAT is not restricted to the kidney allograft recipients but can occur in practically all solid organs transplantation including those patients that have received lungs, liver and heart allograft [1-3]. Guidelines for NODAT were published in 2003 [4]. NODAT is present when persistent hyperglycemia occurs in the period after transplantation in an individual who was previously a non-diabetic. Diabetes mellitus in transplant recipients greatly increases the already elevated risk profile of cardiovascular disease, graft loss and death. The criteria for the diagnosis of diabetes mellitus in the post-transplant period are the same as those set out by the American Diabetes Association (ADA) for the definition of diabetes mellitus in clinical practice [5]. NODAT in effect encumbers the patient with both the usual complications of diabetes such as retinopathy, neuropathy and nephropathy in addition to those complications that are unique to the allograft recipient. Diabetes mellitus is more common in transplant recipients than in the general population with some estimating that there is a nine-fold increase in the risk of diabetes in solid organ recipients than their age-matched controls. Up to $40 \%$ of patients with NODAT will require insulin therapy. The majority of patients however, have features of type-2 DM and do not require insulin [6]. There are disparities in the reported frequencies of NODAT that could be related to geographic, ethnic or socioeconomic peculiarities of the study population. Moreover, the design of the study from which the frequency of occurrence of NODAT was reported is to be considered while comparing prevalence rates. Studies that reported retros- pective analysis of a data base often state the cumulative frequencies while some others have tended to differentiate the prevalence rates on temporal basis thus separating early, late and transient NODAT patient-groups. For example Hur et al. reported an overall incidence of NODAT of $39 \%$ at one year and $35.1 \%$ at seven years for NODAT but went on to differentiate between persistent NODAT (23.4\%) who had hyperglycemia within the first year of transplantation that continued to the seventh year post-transplant [7]. The development of NODAT does not increase risk of death-censored graft loss [8].

\section{Patient and Methods}

Between March 1976, and November 2010, a total of 2019 patients received live-donor renal allograft at our center. Among these recipients, 450 (22.2\%) recipients developed NODAT, (diabetic group). NODAT was diagnosed when fasting blood sugar $\geq 126 \mathrm{mg} /$ $\mathrm{dl}$, random blood sugar or $2 \mathrm{HPP} \geq 200 \mathrm{mg} / \mathrm{dl}$. The NODAT group was retrospectively analyzed and compared with a control group of (455) non diabetic kidney transplant recipients selected from the transplant registry field by date of operation to be matched with the NODAT group regarding the transplantation timing (same week of operation).

*Corresponding author: Ayman Maher Nagib, Consultant of Nephrology, Urology and Nephrology Center, Mansoura 35516, Egypt, Tel: 20-50-/ 0020507481255 Fax: 0020502202717; E-mail: ayman_maher2005@yahoo.com

Received January 22, 2015; Accepted February 21, 2015; Published February 28, 2015

Citation: Nagib AM, Refaie AF, Akl Al, Neamatalla AH, Fouda MA, et al. (2015) New Onset Diabetes Mellitus after Living Donor Renal Transplantation: A Unique Pattern in the Egyptian Population. J Diabetes Metab 6: 519. doi:10.4172/2155 6156.1000519

Copyright: $\odot 2015$ Nagib AM, et al. This is an open-access article distributed unde the terms of the Creative Commons Attribution License, which permits unrestricted use, distribution, and reproduction in any medium, provided the original author and source are credited. 
A number of variables were studied in both groups. These variables includes recipient's age and sex, donor's age and sex, family history of DM, Body Mass Index (BMI), HLA matching, HCV antibody status at time of transplantation. Also the immunosuppressive agents, type of maintenance therapy, total dose of steroids in the first three months and the number of steroid pulses given. Serum creatinine was estimated at 3 month, 6 month and 12 month post-transplantation for both groups. Medical complications which developed post-transplant such as hypertension, hyperlipidemia, proteinuria, ischemic heart disease, neurological complications, retinopathy, and pancreatitis were carefully studied in both groups. Finally, both graft and patient survivals were analyzed.

\section{Statistical analysis}

Qualitative data were displayed in cross tabulation and quantitative data were described in terms of arithmetic mean \pm SD. Bivariate techniques were used for initial evaluation of contrasts. Thus, the chi-square and Fisher's exact tests were used for comparisons of frequencies of qualitative variables and the unpaired ( $t$ ) test was used for comparisons of means two quantitative variables. A P value of less than 0.05 was considered significant. Means were compared by Student (t) test or the non-parametric test if the variable was not normally distributed. Cox's multivariate analysis was made for statistically significant data on univariate analysis. Patient and graft survivals were compared by means of Kaplan-Meier curve, using the log-rank test. All analyses were carried out using the computer package SPSS for windows, release 10 SPSS Inc Chicago, III, USA, 1993.

\section{Results}

Among 2019 renal allograft recipients, 450 recipients (22.2\%) developed NODAT. Characteristics of donors and recipients at the time of transplantation are shown in Table 1. The NODAT recipients were significantly obese body mass index (BMI) $28.8 \pm 9.6$ Vs $25.2 \pm 4.3$ in the control, $\mathrm{P}<0.01$ ). Family history of $\mathrm{DM}$ was significantly positive among the NODAT group (216 Vs 64, $\mathrm{P}<0.01)$. There was 189 (42\%) cases discovered in the first 3 months post transplantation, 37(8.3\%) after 3 to 6 months, 47(10.4\%) after 6 months up to one year, and 177 (39.3\%) after 12 months from the transplantation (Figure 1). Hepatitis $\mathrm{C}$ virus infection (HCV) was significantly more prevalent among our diabetic recipients ( 134 vs $72 \mathrm{P}=.01$ ), Also total doses of steroids were significantly higher among the diabetic group in the univariate analysis only. Cox's multivariate regression analysis of the risk factors was carried out and revealed that the older age of recipients is the most important one followed by positive family history of diabetes mellitus, BMI above 25 and ultimately HCV (Table 2). Coronary heart disease was evaluated in both groups via clinical symptoms, electrocardiogram (ECG) and cardiac enzymes in some cases. The NODAT recipients suffered from significant ischemia, 125 versus the control recipients 47 of the controls $(\mathrm{p}=<0.01)$. Hypercholesterolemia was significantly encountered among the NODAT recipients 100 versus 45 of the controls $(\mathrm{P}=<0.01)$. Arterial blood pressure was evaluated in both groups pre and post transplantation, erect and supine. The NODAT group were more hypertensive post-transplant 304 (67.5\%) versus $249(54.6 \%)$ in control group $(\mathrm{P}=<0.01)$. However pre transplant, hypertension was comparable among the two groups. Post-transplant complications named retinopathy; infection and pancreatitis also significantly dominate in the NODAT (Table 3 ). The difference in the serum creatinine initially tends to be better in the NODAT recipients but at last follow up it was in NODAT group versus the control recipients. Graft survival was comparable in the two groups $(\mathrm{p}=0.738)$ (Figure 2), Proteinuria was significantly higher among the NODAT group even there were 6 patient had biopsies proven post-transplant diabetic nephropathy. Patient survival was significantly less in the diabetic group $(\mathrm{P}<0.046)$ (Figure 3$)$.

\section{Discussion}

The prevalence of diabetes mellitus is rapidly increasing worldwide, as a consequence of western life style and Diabetes currently affects

\begin{tabular}{|c|c|c|c|}
\hline Variable & $\begin{array}{l}\text { Diabetic group } \\
\qquad N=450\end{array}$ & $\begin{array}{l}\text { Control group } \\
N=456\end{array}$ & $P$ value \\
\hline Follow up period (years) & $8.8 \pm 5.8(7.8)$ & $7.7 \pm 6.0(6.3)$ & \\
\hline $\begin{array}{l}\text { Recipients } \\
\text { Age (years) } \\
\text { Sex (M/F) } \\
\text { Body mass index (BMI) }\end{array}$ & $\begin{array}{l}35.2 \pm 9.9 \\
351 / 99 \\
28.8 \pm 4.6\end{array}$ & $\begin{array}{c}28 \pm 9.6 \\
340 / 116 \\
25.2 \pm 4.3\end{array}$ & $\begin{array}{l}<0.01 \\
0.140 \\
<0.01\end{array}$ \\
\hline $\begin{array}{l}\text { Donors } \\
\text { Age (years) } \\
\text { Sex (M/F) } \\
\text { Consanguinity } \\
\text { Related/unrelated } \\
\text { HLA-DR } \\
\text { One match } \\
\text { Two match } \\
\text { Not determined }\end{array}$ & $\begin{array}{c}34.4 \pm 9.2 \\
309 / 141 \\
346 / 104 \\
391(86.8 \%) \\
49(10.8 \%) \\
10(2.22 \%)\end{array}$ & $\begin{array}{c}35.5 \pm 10.2 \\
314 / 142 \\
377 / 79 \\
\\
406(89.03 \%) \\
44(9.64 \%) \\
6(1.31 \%)\end{array}$ & $\begin{array}{l}0.115 \\
0.456 \\
0.15\end{array}$ \\
\hline Family history of DM & $216(86.4 \%)$ & $64(25 \%)$ & $<0.01$ \\
\hline $\begin{array}{l}\text { Number of transplant } \\
\text { received First } \\
\text { Second }\end{array}$ & $\begin{array}{c}430(95.5 \%) \\
20(4.5 \%)\end{array}$ & $\begin{array}{c}437(95.8 \%) \\
19(4.2 \%)\end{array}$ & 0.486 \\
\hline Total dose of steroids & $6.35 \pm 3.1 \mathrm{gms}$ & $5.8 \pm 3.4 \mathrm{gms}$ & 0.047 \\
\hline
\end{tabular}

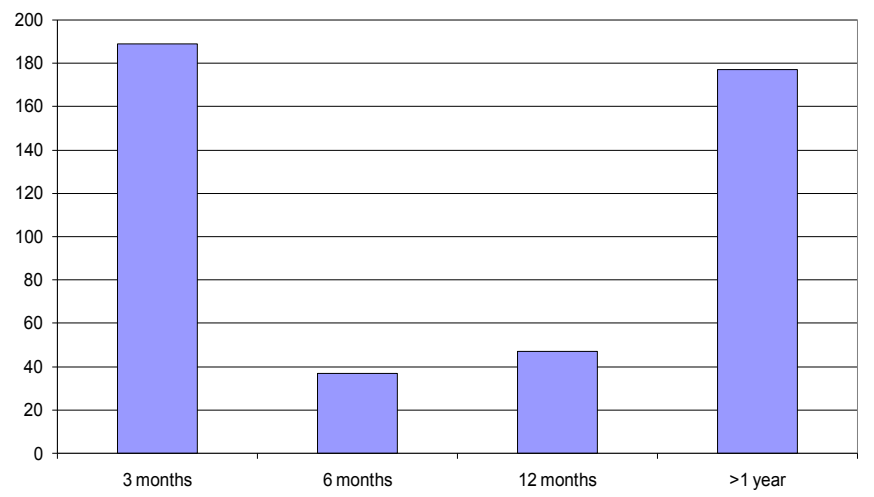

Figure 1: Onset of DM post-transplantation: There were 224 cases discovered in the first 6 months post transplantation, 48 after 6 months up to one year and 178 after 12 months from the transplantation.

\begin{tabular}{|c|c|c|c|c|}
\hline Characteristic & $\begin{array}{l}\text { Regression } \\
\text { Estimate (B) }\end{array}$ & S.E. & $\begin{array}{l}\text { Relative Risk } \\
\text { Exp. (B) }\end{array}$ & P-Value \\
\hline $\begin{array}{l}\text { Age }<40 \text { years } \\
\text { Age }>40 \text { years }\end{array}$ & $\overline{1.46}$ & $\overline{0.36}$ & 4.31 & $<0.01$ \\
\hline $\begin{array}{l}\text { Negative family history } \\
\text { Positive family history }\end{array}$ & -1.63 & 0.31 & 0.2 & $<0.01$ \\
\hline $\begin{array}{l}\mathrm{BMI} \leq 25 \\
\mathrm{BMI}>25 \\
\text { Hypercholesterolemia } \\
\mathrm{HCV}\end{array}$ & \begin{tabular}{|l|}
-- \\
1.66 \\
--- \\
-0.75 \\
-- \\
0.81
\end{tabular} & \begin{tabular}{l}
-- \\
0.27 \\
\hdashline-- \\
0.35 \\
\hdashline-- \\
0.27
\end{tabular} & $\begin{array}{l}--- \\
.24 \\
--- \\
0.47 \\
--- \\
2.24\end{array}$ & \begin{tabular}{l}
--- \\
$<0.01$ \\
\hdashline$-\overline{0.03}$ \\
--- \\
$<0.01$
\end{tabular} \\
\hline
\end{tabular}

Table 2: Multivariate analysis of risk factors. 


\begin{tabular}{|c|c|c|c|}
\hline Variable & $\begin{array}{l}\text { Diabetic group } \\
\qquad N=450\end{array}$ & $\begin{array}{c}\text { Control group } \\
\qquad=456\end{array}$ & $P$ value \\
\hline Post-transplant Hypertension & $304(67.5 \%)$ & $249(54.6 \%)$ & $<0.01$ \\
\hline Hypercholesterolemia & $100(22.2 \%)$ & $45(9.8 \%)$ & $<0.01$ \\
\hline Ischemic heart disease & $125(27.7 \%)$ & $47(10.3 \%)$ & $<0.01$ \\
\hline Proteinuria & $275(61.1 \%)$ & $198(43.4 \%)$ & $<0.01$ \\
\hline \multicolumn{4}{|l|}{ Neurological complication : } \\
\hline $\begin{array}{l}\text { Cerebral strokes: } \\
\text { Peripheral neuropathy: }\end{array}$ & $9(2 \%)$ & $4(0.87 \%)$ & $<0.01$ \\
\hline Sensory & $30(6.66 \%)$ & $1(0.21 \%)$ & $<0.01$ \\
\hline Motor & $7(1.5 \%)$ & $4(0.87 \%)$ & $<0.01$ \\
\hline Autonomic & $9(2 \%)$ & $20(4.3 \%)$ & $<0.01$ \\
\hline Combined & $109(24.2 \%)$ & $11(2.4 \%)$ & $<0.01$ \\
\hline Retinopathy & $37(8.22 \%)$ & 0 & $<0.01$ \\
\hline Malignancy & $8(1.9 \%)$ & $15(3.28 \%)$ & 0.344 \\
\hline Pancreatitis & $5(1.1 \%)$ & 0 & $<0.01$ \\
\hline Bacterial infections: & $55(12.22 \%)$ & $37(8.11 \%)$ & 0.027 \\
\hline Viral infection:(HCV) & $134(29.77 \%)$ & $72(15.7 \%)$ & $<0.01$ \\
\hline
\end{tabular}

Table 3: Medical complications.

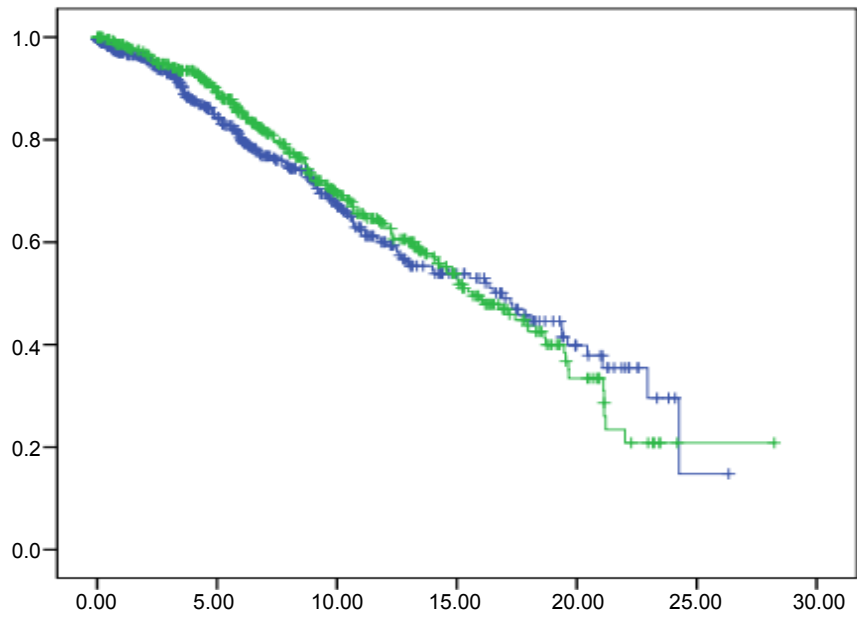

Figure 2: Graft survival. Figure (2) shows Kaplan-Meier curve for graft survival in all recipients within the follow-up period. Graft survival was comparable in the two groups $(p=0.738)$.

over 346 million people worldwide. Transplantation may accelerate the development of type 2 diabetes in individuals at risk (WHO, august, 2011). In our study, the incidence of NODAT was $22.2 \%$ which compares closely to that reported being $16-24 \%$ [9]. This discrepancy may be attributed to; variable number of patients, racial, different protocols of immunosuppressive agents employed in the management of these patients and different follow up periods. The onset of NODAT among our recipients was predominantly in the first six months post transplantation (50.3\%) and this in accordance with that reported previously $[10,11]$. These findings may be explained by stress, surgery, relatively larger doses of corticosteroids in the early post transplantation period.

The mean age of NODAT group was significantly higher than the control group $(35.2 \pm 9.9$ vS $28 \pm 9.6$ years, $\mathrm{P}=0.001)$. Moreover $28 \%$ of NODAT recipients were above the age of 40 years versus $10 \%$ in the controls $(\mathrm{P}=0.0001)$. These results agree with that reported [12] and disagree with that previously reported, who find the incidence of NODAT dominate among the age above 45 years [13]. This difference can be attributed to Egyptian selection of younger age recipients that is expected to resume professional activities after being transplanted. In an attempt to find out the possible factors which may play a role in the development of NODAT several variables were studied. We found that the prevalence of positive family history of DM is significantly higher among the NODAT recipients ( 216 vs 64 of controls $\mathrm{P}=0.001$ ) this accords with that cited in literatures [14-16]. Also, we found a significant correlation between NODAT and obesity evaluated by BMI $(28.8 \pm 9.6$ vs $25.2 \pm 4.3$, of controls $\mathrm{P}=0.001)$. Our results are similar to that reported $[15,17,18]$. However, Sumrani et al., and Montori et al., [8] found no correlation between NODAT and obesity in transplant recipients. These findings could be explained by racial difference and different life styles of the studied Egyptian patients.

Hepatitis C virus infection was significantly more prevalent among our NODAT recipients ( 134 vs $72, \mathrm{P}=0.01$ ) (Table 3 ), this is in accordance with that reported [9], whom found unadjusted cumulative incidences of $15.6 \%, 25.6 \%$ and $35.4 \%$ at 3,12 , and 36 months respectively for diabetes after kidney transplantation for patients who were $\mathrm{HCV}$ positive at transplantation compared with $8.8 \%, 15.4 \%$, and $23.4 \%$ for HCV negative patients, $(\mathrm{p}<0.0001)$. Moreover, Gentil et al. reported that NODAT was predominant among HCV positive recipients ( $28 \%$ vs $6.2 \%, \mathrm{p}=0.001)$ [17]. The relatively high incidence of NODAT among HCV positive patients may be explained by a direct or immune-mediated effect on B cells of pancreatic islets [19]. Over the last three decades, different immunosuppressive protocols were adopted in our center since we started renal transplantation at 1976 . We found a significant correlation between NODAT and total dose of steroids in the first 3 months $(6.35 \pm 3.1$ gms vs $5.8 \pm 3.4 \mathrm{gms} ; \mathrm{P}=0.047)$ and, total doses of pulses of steroids needed to manage rejection ( $562.5 \mathrm{gms}$ vs 570 gms; $\mathrm{P}=0.03$ ) since rejection episodes (51.3\% vs $43.7 \%$; $\mathrm{P}=0.01$ ). Our results agree with that reported [20-22]. The macro vascular complications of diabetes pose a major threat to patient survival. The risk of stroke in patients with diabetes is 2-4 folds greater than in the general population. Also patients with DM have a greater mortality risk than the general population largely due to increased mortality rates from CVD and cerebrovascular disease secondary to accelerated atherosclerotic process [23,24]. Cardiovascular disease is the commonest cause of death after kidney transplantation, and diabetes is one of the major risk factors for its development [25,26]. In our study we found a significant correlation between NODAT and coronary heart disease, ( 125 vs 47 of controls; $\mathrm{P}=0.01$ ). These results are in accordance to that reported in the literatures [27]. Moreover, we found that the incidence

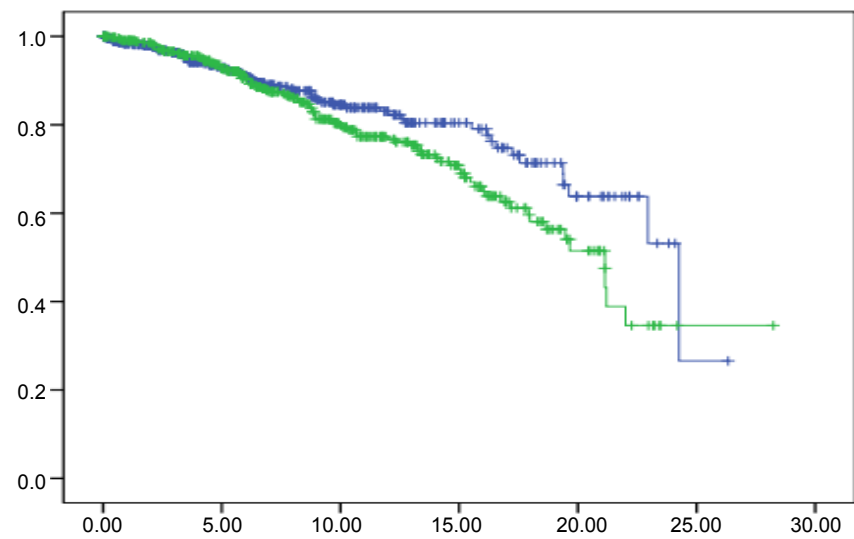

Figure 3: Patient survival. Figure (3) shows Kaplan-Meier curve for patient survival in all recipients within the follow-up period. Patient survival was significantly less in the NODAT group $(P=0.046)$. 
of the mortality with functioning graft secondary to cardiovascular cause is more among NODAT (23.5 vs $15.8 \%$ in controls; $\mathrm{P}=0.05$ ). These results agree with that reported [28]. This could be explained by the prevalence of post transplantation hypertension (304 vs 249; $\mathrm{P}=0.02$ ), hypercholesterolemia among the diabetics recipients (100 vs $45 ; \mathrm{P}=0.001)$, the older age of NODAT recipients $(35.2 \pm 9.9$ vs $28 \pm$ 9.6 years; $\mathrm{P}=0.001)$ and the obesity among the NODAT group $(28.8$ \pm 9.6 vs $25.2 \pm 4.3$, of controls; $\mathrm{P}=0.001$ ). In our study, acute diabetic complications that require hospitalization (diabetic ketoacidosis and non ketotic hyperglycemic hyperosmolar states) occurred in 5.1\% of our recipients, this result is higher than that reported [29] being $2.3 \%$. This discrepancy may be attributed to shorter duration of follow up period in their study and the relatively poor compliance of our NODAT recipients. Retinopathy is a point of concern, since only $8.2 \%$ of our NODAT recipients suffered diabetic retinopathy. This was less than that reported [30] ( $8 \%$ at 3 years, $25 \%$ at 5 years, $60 \%$ at 10 years, and $80 \%$ at 15 years) and could be explained by the relatively shorter follow up period ( $7 \pm 5$ years) in our study. Proteinuria was significantly prevalent among the NODAT (275 vs $198 ; \mathrm{P}=0.001)$, also the degree of proteinuria tends to be more severe in the diabetics. Among the NODAT proteinuric recipients, 6 patients showed diabetic nephropathy proved by histo-pathological examination. Neuropathy, either peripheral and/or autonomic was prevalent among our NODAT group (109 vs 11; $\mathrm{P}=0.001$ ), Similar figures were reported (41.9\%) [31]. However, Lower incidence was reported (30\%) [32], which could be explained by different follow up periods, pre-transplant uremic period, and variable recipient's ages in the different studies. Moreover, cerebral strokes showed significant correlation to NODAT ( 9 vs $4 \mathrm{p}=0.01$ ), these results are in accordance to that reported [33]. The incidence of infection necessitating hospitalization was found to be significantly higher among our NODAT recipients ( 55 vs $37 \mathrm{P}=0.03$ ). These results agree with that reported [12] being $54 \%$ vs $17 \%$ in the control group. These results may be due to the use of different immunosuppressive protocols, different follow up period and relatively poor compliance of our diabetic recipients. We found a significant correlation between NODAT and malignancy being ( 15 vs $8 ; \mathrm{P}=0.34$ ). Similar data were reported in the literature [34]. In the contrary, Danpanich and Kasiske [35] reported that recipients with type 1 diabetes (pre-transplantation) associated with lower incidence of malignancy. This could be explained by higher prevalence of HCV among our NODAT recipients ( 3 cases had hepatocellular carcinomas; $\mathrm{P}=0.01)$. Also we found 5 cases of pancreatitis among our NODAT recipients (1.1\%). Similar data, being (1.2\%-6.8\%) reviewed [36]. The numbers of potential risk factors in addition to those of the general population are perpetuated by number of other factors, uremia, and disorder of lipid metabolism, polycystic kidney, immunosuppressive drugs, and cytomegalovirus infection [36]. In our study, graft survival was comparable in both groups until 15 years post-transplantation. Then graft survival was markedly declined in the NODAT recipients $(43.5 \%$ vs $53.6 \% ; \mathrm{P}=0.013)$. These results came parallel to that reported in the literature being ( $48 \%$ vs $70 \%$; $\mathrm{P}<0.001)$ at 12 years. In contrast, our results disagree with that reported [37] considering graft survival after 3 and 4 years incurs significant difference being $(71 \%$ vs $86 \%$ and $54 \%$ vs $82 \%$; $\mathrm{P}<0.001)$ respectively due to high incidence of acute rejection and uncontrolled hypertension among the diabetic recipients. These differences could be attributed to the fact that diabetic nephropathy needs several years to develop and may not account for the early graft failure. Also, the attempts to decrease the dose of immunosuppressive drugs to control diabetes and its complications may be account for increased long-term graft failure due to chronic allograft nephropathy [38]. On analyzing the patient survival in our study, we didn't find a significant difference in the first
8 years post-transplantation. Thereafter, a significant decline in patient survival among NODAT was prominent ( 79.9 vs $86.1 \% ; \mathrm{p}=0.001)$ and continue to decline down to 15 years post transplantation $(60.6 \%$ vs $77.8 \%$; $\mathrm{P}<0.001)$. Moreover, graft survival after 20 years showed $(24 \%$ vs $70.3 \% ; \mathrm{P}<0.001$ ) of the control recipients. These results are similar to that reported in the literature [39]. Finally, a strong argument in favor of a deleterious effect of diabetes on post-transplantation outcome is the fact that the long-term survival of patients with diabetes who undergo simultaneous pancreas-kidney transplantation has been improved (8-year survival rates of $72 \%$ for pancreas-kidney recipients vs $55 \%$ for cadaveric kidney recipients) [40]. The deleterious effect of NODAT on the patient survival could be attributed to predominance of CVD, cerebrovascular disease, infections and malignancy among the diabetic recipients. At last, the management of NODAT is not different from that of patients with DM, comprising of diet regimen to initiate therapy and, if not sufficient to achieve glycemic control, addition of oral hypoglycemic and ultimately if insufficient insulin therapy is commenced. The same recommendations were reported in several literatures, as uncontrolled DM may affect the patient as well as graft survival [41,42].

\section{Conclusion}

NODAT has a unique pattern among Egyptian populations regarding risk factors especially older age, positive family history, obesity and HCV infection. NODAT has no statistical significant affection on graft survival. Meanwhile, NODAT is a major problem endangers the patient life and must be minded to consider such patient as especially at higher risk for diabetic complications.

\section{References}

1. Ollech JE, Kramer MR, Peled N, Ollech A, Amital A, et al. (2008) Post-transplant diabetes mellitus in lung transplant recipients: incidence and risk factors. Eur $J$ Cardiothorac Surg 33: 844-848.

2. Hathout E, Alonso E, Anand R, Martz K, Imseis E, et al. (2007) Post-transplant diabetes mellitus in pediatric liver transplantation. Pediatr Tranplant 13: 599605

3. Garlicki M (2005) Post-transplant diabetes mellitus (PTDM) in heart recipients Ann Transplant 10: 51-53.

4. Davidson J, Wilkinson A, Dantal J, Dotta F, Haller H, et al (2003) Newonset Diabetes after transplantation: International consensus guidelines. Transplantation 75: SS1-SS11.

5. American Diabetes Association (2004) Diagnosis and classification of diabetes mellitus. Diabetes Care 27 Suppl 1: S5-5S10.

6. Campise M (2007) Post transplant diabetes mellitus; Diagnosis and treatment $G$ Ital Nefrol 24: 47-57.

7. Hur KY, Kim MS, Kim YS, Kang ES, Nam JH, et al. (2007) Risk factors associated with the onset and progression of posttransplation diabetes in renal allograft recipients. Diabetes Care 30: 609-615.

8. Montori VM, Basu A, Erwin PJ, Velosa JA, Gabriel SE, et al. (2002) Posttransplantation diabetes: a systematic review of the literature. Diabetes Care 25: 583-592.

9. Kasiske BL, Snyder JJ, Gilbertson D, Matas AJ (2003) Diabetes mellitus after kidney transplantation in the United States. Am J Transplant 3: 1-8.

10. Chakkera HA, Chang YH, Ayub A, Gonwa TA, Weil EJ, et al. (2013) Validation of a pretransplant risk score for new-onset diabetes after kidney transplantation. Diabetes Care 36: 2881-2886.

11. Cosio FG, Pesavento TE, OseiK, Henry ML, Ferguson RM (2001)Posttransplant diabetes mellitus: increasing incidence in renal allograft recipients transplanted in recent years. Kidney Int 59: 732-737.

12. Reisaeter AV, Hartmann A (2001) Risk factors and incidence of posttransplant diabetes mellitus. Transplant Proc 33: 8S-18S.

13. Boudreaux JP, McHugh L, Canafax DM, Ascher N, Sutherland DE, et al. 
Citation: Nagib AM, Refaie AF, Akl Al, Neamatalla AH, Fouda MA, et al. (2015) New Onset Diabetes Mellitus after Living Donor Renal Transplantation: A Unique Pattern in the Egyptian Population. J Diabetes Metab 6: 519. doi:10.4172/2155-6156.1000519

(1987) The impact of cyclosporine and combination immunosuppression on the incidence of posttransplant diabetes in renal allograft recipients. Transplantation 44: 376-381.

14. Razeghi E, Heydarian P, Amerian M, Pourmand G (2010) The risk factors for diabetes mellitus after kidney transplantation. Saudi J Kidney Dis Transpl 21: 1038-1043.

15. Miles AM, Sumrani N, Horowitz R, Homel P, Maursky V, et al. (1998) Diabetes mellitus after renal transplantation: as deleterious as non-transplant-associated diabetes? Transplantation 65: 380-384.

16. Caillard S, Eprinchard L, Perrin P, Braun L, Heibel F, et al. (2011) Incidence and risk factors of glucose metabolism disorders in kidney transplant recipients: role of systematic screening by oral glucose tolerance test. Transplantation 91 757-764.

17. Gentil MA, Lopez M, Gonzalez-Roncero F, Rodriguez-Algarra G (2003) Hepatitic $C$ and the incidence of diabetes mellitus after renal transplant: influence of new immunosupression protocols. Transplant proc. 35: 1748-1750.

18. Luan FL, Steffick DE, Ojo AO (2011) New-onset diabetes mellitus in kidney transplant recipients discharged on steroid-free immunosuppression. Transplantation 91: 334-341.

19. Knobler H, Stagnaro-Green A, Wallenstein S, Schwartz M, Roman SH (1998) Higher incidence of diabetes in liver transplant recipients with hepatitis $\mathrm{C}$. J Clin Gastroenterol 26: 30-33.

20. Hjelmesaeth J, Hartmann A, Kofstad J, Egeland T, Stenstrom J, et al. (2001) Tapering off prednisolone and cyclosporine the first year after renal transplantation: the effect on glucose tolerance. Nephrol Dial Transplant 16: 829-835.

21. Bloom RD, Crutchlow MF (2008) New-onset diabetes mellitus in the kidney recipient: diagnosis and management strategies. Clin J Am Soc Nephrol 3 Suppl 2: S38-48.

22. Johnston O, Rose CL, Webster AC, Gill JS (2008) Sirolimus is associated with new-onset diabetes in kidney transplant recipients. J Am Soc Nephrol 19: 1411-1418.

23. Stamler J, Wentworth D, Vaccaro O, Neaton JD (1993) Diabetes, other risk factors, and 12-yr cardiovascular mortality for men screened in multiple risk factor intervention trial. Diabetes Care 16: 434-444.

24. Grundy SM, Benjamin IJ, Burke GL, Chait A, Eckel RH, et al. (1999) Diabetes and cardiovascular disease: A statement for healthcare professionals from the American Heart Association. Circulation 100: 1134-1146.

25. Geiss LS, Herman WH, Smith PJ (1995) National Diabetes Data Group. Diabetes in America. Bethseda. Md: National Institutes of Health. National Institutes of Diabetes and Digestive and Kidney Diseases: 233-257.

26. Wauters RP, Cosio FG, Suarez Fernandez ML, Kudva Y, Shah P, et al. (2012) Cardiovascular consequences of new-onset hyperglycemia after kidney transplantation. Transplantation 94: 377.
27. Lindholm A, Albrechtsen D, Frodin L, Persson NH, Lundgren $G$ (1995) Ischemic heart disease -major cause of death and graft loss after renal transplantation in Scandinavia. Transplantation 60: 451-457.

28. Foley RN, Parfrey PS, Sarnak MJ (1998) Clinical epidemiology of cardiovascular disease in chronic renal disease. Am J Kidney Dis 32: S112-119.

29. Abbott KC, Bernet VJ, Agodoa LY, Yuan CM (2003) Diabetic ketoacidosis and hyperglycemic hyperosmolar syndrome after renal transplantation in the United states. BMC Endocrine Disorders 3: 1

30. American Diabetes Association (2002) Treatment of hypertension in adults with diabetes. Diabetes Care 25: S71-73.

31. Partanen J, Niskanen L, Lehtinen J, Mervaala E, Siitonen O, et al. (1995) Natural history of peripheral neuropathy in patients with non-insulin-dependent diabetes mellitus. N Engl J Med 333: 89-94.

32. Young MJ, Boulton AJ, MacLeod AF, Williams DR, Sonksen PH (1993) A multicentre study of the prevalence of diabetic peripheral neuropathy in the United Kingdom hospital clinic population. Diabetologia 36: 150.

33. Kasiske BL, Guijarro C, Massy ZA, Wiederkehr MR, Ma JZ (1996) Cardiovascular disease after renal transplantation. J Am Soc Nephrol 7: 158-165

34. Mieghem AV, Fonck C, Coosemans W, Vandeleene B, Vanrenterghem Y, et al. (2001) Outcome of cadaver kidney transplantation in 23 patients with type 2 diabetes mellitus. Nephrol Dial Transplant 16: 1686-1691.

35. Danpanich E, Kasiske BL (1999) Risk factors for cancer in renal transplant recipients. Transplantation 68: 1859-1864.

36. Asztalos L, Kincses Z, Berczi C, Szabo L, Fedor R, et al. (2001) [Acute pancreatitis after kidney transplantation]. Magy Seb 54: 91-94.

37. Roth D, Milgrom M, Esquenazi V, Fuller L, Burke G, et al. (1989) Posttransplant hyperglycemia. Increased incidence in cyclosporine-treated renal allograft recipients. Transplantation 47: 278-281.

38. Weir MR, Fink JC (1999) Risk for posttransplant Diabetes mellitus with current immunosuppressive medications. Am J Kidney Dis 34: 1-13.

39. Demirci MS, Toz H, Yilmaz F, Ertilav M, Asci G, et al. (2010) Risk factors and consequences of post-transplant diabetes mellitus. Clin Transplant 24: E170177

40. Reddy KS, STablein D, Taranto S, Stratta RJ, Johnston TD, et al. (2003) Longterm survival following simultaneous kidney- pancreas transplantation versus kidney transplantation alone in patients with type 1 diabetes mellitus and renal failure. Am J Kidney Dis 41:464.

41. Luna B, Feinglos MN (2001) Oral agents in the management of type 2 diabetes mellitus. Am Fam Physician 63: 1747-1756.

42. Expert Committee on the Diagnosis and Classification of Diabetes Mellitus (2003) Report of the expert committee on the diagnosis and classification of diabetes mellitus. Diabetes Care 26 Suppl 1: S5-20. 